\title{
Proposal of New Zoning Concept Considering Lightning Protection of Wind Turbine Blades
}

\author{
S.F. Madsen*, K. Bertelsen, T.H. Krogh, H.V. Erichsen, A.N. Hansen and K.B. Lønbæk
}

Global Lightning Protection Services A/S, Lejre, Denmark

\begin{abstract}
Lightning protection of wind turbines has gained increased interest during the past ten years. The characteristics of a modern wind turbine exhibiting overall heights of $150 \mathrm{~m}$, moving blades with a tip velocity of $60-80$ $\mathrm{m} / \mathrm{s}$, a wide use of insulating and conducting composite materials dictates the challenges faced by the lightning protection engineer. The present paper discusses a new method of dividing wind turbine blades in different zones, to argue for a principle of differentiating the lightning protection system. The methodology counteracts the traditional interpretation of the Electro Geometrical Model (EGM) for blades in IEC TR 61400-24 (2002) but follows the needs for new approaches given in the IEC 61400-24 (2010). The argumentation is based on experiences gathered during the past five years, consisting of laboratory testing, numerical modeling and gathering of field data. Finally the conclusions are correlated with the requirements in the new standard concerning lightning protection of wind turbines; IEC 61400-24.
\end{abstract}

Keywords: Blades, IEC 61400-24, lightning protection, lightning zoning, wind turbines.

\section{INTRODUCTION}

The present lightning protection standard IEC 61400-24 [1] defines the entire surface of the blade to be within Lightning Protection Zone 0A. However, recent field experience of actual lightning attachments to blades, numerical modeling of attachment points and attachment probability distributions on blades, and a theoretical review of the most recent research on the subject, shows that this interpretation might be too pessimistic. Apparently the blade tips are far more exposed than the blade section only a few meters inboard, why this should be reflected in a different zoning concept and hence a differentiated protection.

This paper defines a new zoning concept where the tip of the blade is treated as a different zone than the remaining part of the blade. In the report the background of the new zoning concept is explained, and the principle is demonstrated used on existing blade designs.

\section{ATTACHMENT PROCESS}

A lightning discharge consists of several subsequent steps, where the first one in engineering applications is the attachment process. This process occurs in two different ways depending on where the lightning leader origins.

1. If the lightning leader origins in the clouds above the turbine, in the case of a downward initiated strike, the attachment process occurs in vicinity of the grounded structure. In this case the Electro Geometric Model (EGM) is often used to explain the processes and to link them to the charge, the peak current, striking distances, etc.

*Address correspondence to this author at the Global Lightning Protection Services A/S, Højbyvej 19, DK-4320 Lejre, Denmark; Tel: +45 6081 5049;

E-mail: info@highvoltage.dk
2. If the lightning strike is upward initiated, the initial leader is formed at the turbine and propagates upward until it reaches the charge region in the cloud or a cloud connecting leader. In this case the attachment point is dictated by the grounded structure, and cannot be explained by the EGM, the rolling sphere and others.

In traditional lightning protection standards, like the IEC 62305 series [2], the EGM as the rolling sphere, the protective angle and the mesh method is suggested for placing air terminations. This was also the recommendation in the IEC TR 61400-24 from 2002 [3], but in the current revision [1], the rolling sphere method is not to be used for defining attachment points on blades.

\subsection{Downward Initiated Strikes}

For downward initiated strikes, a correlation between the charge in the leader channel and the distance to the structure which eventually will be struck has been found. Since there exist also an empirical correlation between the charge in the leader channel and the peak amplitude current, a formula of the following type has been derived.

$d_{s}=a \cdot\left(I_{p}\right)^{b}$

where ' $\mathrm{d}_{\mathrm{s}}$ ' is the striking distance, ' $\mathrm{I}_{\mathrm{p}}$ ' is the prospective return stroke current, and 'a' and ' $b$ ' are constants. Several values of the two constants have been published by various authors [4]. The ones used by IEC, has been suggested by an IEEE working group in 1992, giving the well known relationship

$d_{s}=10 \cdot\left(I_{p}\right)^{0.65}$

This relationship is used to define the radii of the spheres in the rolling sphere method, such that the striking distance (or the radius of the rolling sphere) can be computed for 
various peak return stroke currents (Table 1). Usually the relationship in (2) only applies to prospective peak currents up to some tens of $\mathrm{kA}$, whereas smaller striking distances as suggested by other authors are more likely for higher peak currents. However, since the IEC 62305 [2] uses this equations and do not give any restrictions on the prospective current, several examples of such values are found in the table below:

Table 1. Return Stroke Current vs Striking Distance

\begin{tabular}{|c|c|}
\hline Return Stroke Current $[\mathbf{k A}]$ & Striking Distance $[\mathbf{m}]$ \\
\hline \hline 10 & 45 \\
\hline 20 & 70 \\
\hline 50 & 127 \\
\hline 100 & 200 \\
\hline 150 & 260 \\
\hline 200 & 313 \\
\hline
\end{tabular}

The lightning protection standard series IEC 62305 [2] only applies the rolling sphere method on land based structures up to $60 \mathrm{~m}$, and in IEC $61400-24$ [1] it is stated that it should not be applied to wind turbine blades.

However, when using the method on structures like wind turbines it is found that the blade tips might experience full amplitude strikes, but that the amplitude will decrease for attachments further inboard close to the root end. In its direct form, the rolling sphere method does not consider attachment point probabilities; it only defines possible points of attachment due to the strict concept of striking distances.

On Fig. (1), the rolling sphere method using a peak current of $65 \mathrm{kA}$ is applied on a wind turbine.

Downward initiated strikes to wind turbines are probably better described using numerical modeling methods as discussed in section 0 , than the traditionally rolling sphere method.

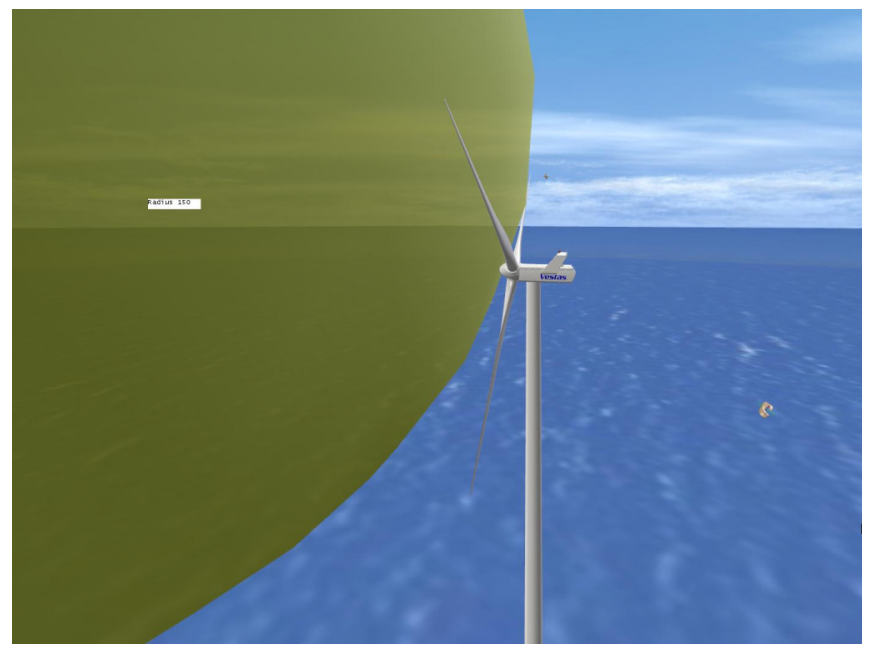

Fig. (1). Rolling sphere method applied on a turbine by Vestas Wind Systems A/S. The radius of the sphere corresponds to a $65 \mathrm{kA}$ lightning strike, apparently the largest amplitude expected to strike the HUB for wind turbines installed on flat ground.

\subsection{Upward Initiated Strikes}

Strikes are said to be upward initiated if the initial leader develops at grounded structures and propagate upwards, until it intercepts with the charge regions in the clouds. Upward lightning mainly occurs to tall structures, since the electric field enhancement around such pointy objects are relatively larger than around more flat geometries. Therefore the ionization field strength for the surrounding air is reached earlier at these places complying with the conditions for inception of the self propagating leader.

Several approaches have been done to quantify the total number of strikes to a structure considering both upward and downward initiated strikes. One of these equations is developed by Eriksson in 1987 [5].

$$
N=24 \cdot 10^{-6} \cdot H_{s}^{2.05} \cdot N_{g}
$$

where ' $\mathrm{H}_{\mathrm{s}}$ ' is the object height in $[\mathrm{m}]$ and $\mathrm{N}_{\mathrm{g}}$ ' is the ground flash density in $1 /\left(\mathrm{km}^{2}\right.$.year $)$. Based on lightning strike data from ten tall structures ranging from $110-540 \mathrm{~m}$, an equation stating the ratio of upward $v s$ downward initiated lightning strikes was published in 1984 by Eriksson.

$P_{u}=52.8 \cdot \ln \left(H_{s}\right)-230$

From this equation it is seen that for structures lower than app. $80 \mathrm{~m}$, only downward initiated strikes are expected, whereas for structures exceeding app. $500 \mathrm{~m}$, only upward initiated strikes occur. The percentages of upward initiated strikes $v s$ structure height are seen on the graph in Fig. (2).

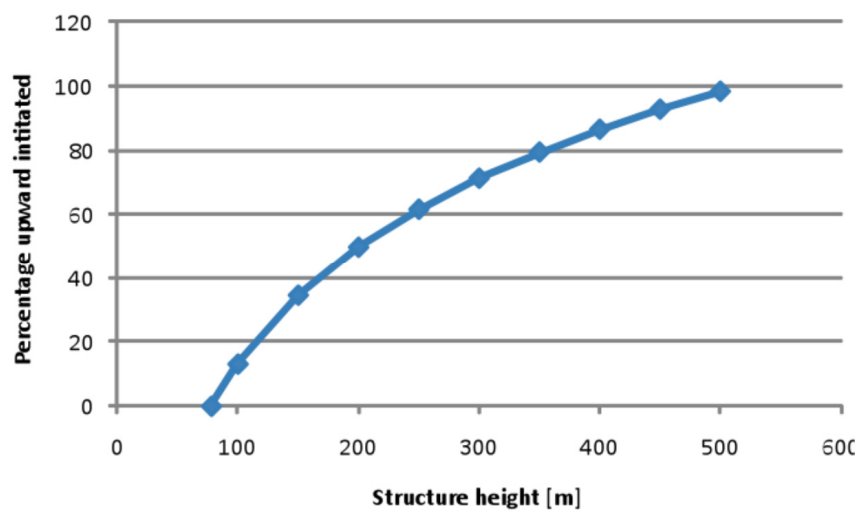

Fig. (2). Ratio of upward initiated strikes [\%] vs structure height [m].

Since upward initiated strikes only occur from the upper pointiest part of the structure, it will be the blade tips on turbines that participate in such processes. Secondly since turbine designs are constantly increasing in size, the fraction of upward initiated strikes and hence the amount of strikes from the blade tips increase similarly.

\subsection{Numerical Modeling}

In 2007 a research project was initiated by Vestas Wind System to find an improved and more valid method of determining lightning attachment points on wind turbines. The research was partly triggered by some very promising findings of the lightning research group led by professor Cooray in Uppsala [6-8], and partly by the revised IEC 61400-24 disregarding the use of the rolling sphere method on blades [1]. 

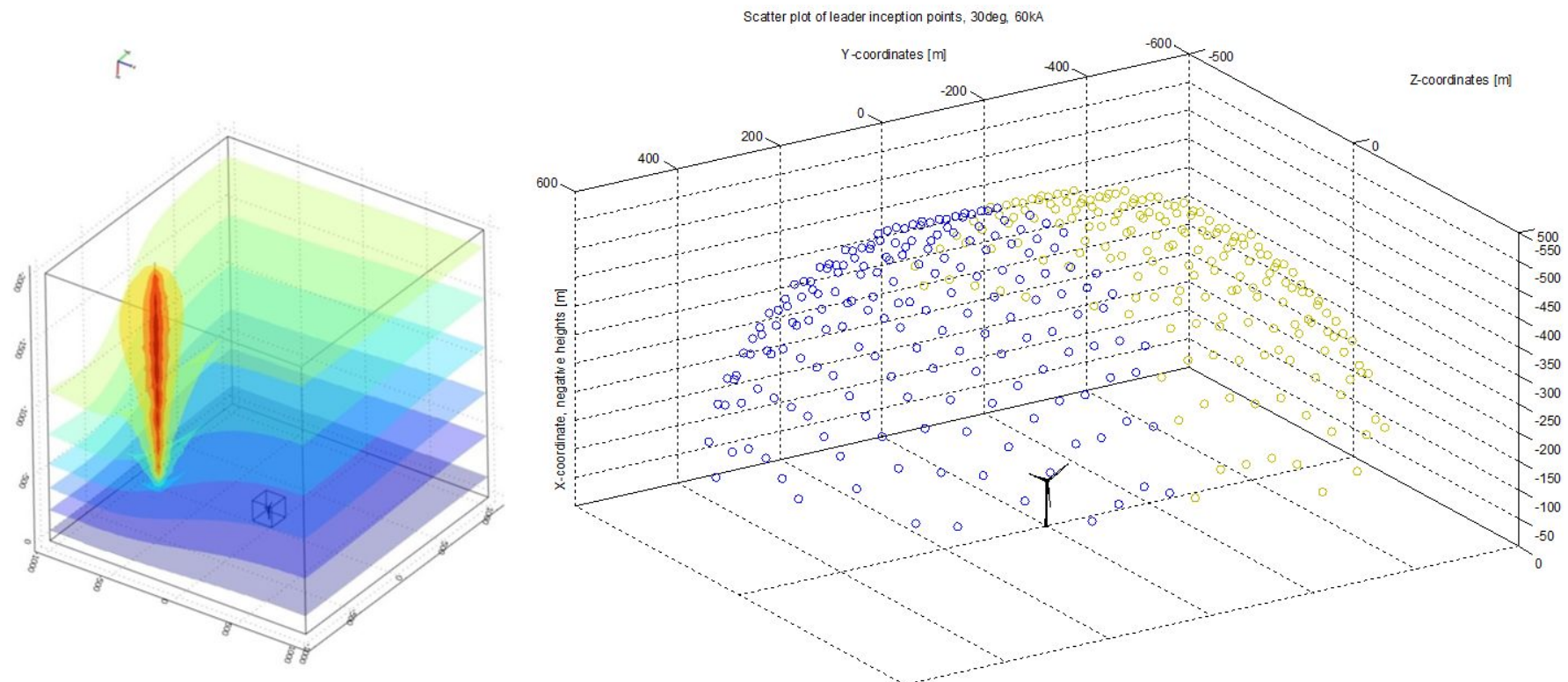

Fig. (3). Visualization of the computations from the attachment point modeling. Left: Equipotential planes plotted between an incoming leader and the grounded turbine, Right: A plot of leader tips when the inception of upward leaders from the turbine occur [11].

The work by Becerra and Cooray describes a numerical model of the upward leader and considers most of the known physical phenomena linked to the discharge formation. The project by Vestas Wind System matured the rather academic findings and implemented them on a wind turbine model. The results from the process were finally extended to attachment probabilities that enable a calculation of which amplitudes of direct lightning strikes that are expected to occur to the different regions of a wind turbine. The entire work was published at three international conferences on lightning protection [9-11].

All the computations were done on a 3D FEM model of a Vestas turbine, and the analysis was conducted by letting lightning leaders approach it from different origins. By carefully evaluating the conditions for inception of corona and streamers at the turbine, and considering the criteria for the transition of these initial discharges into a self propagating leader, an image of the exposed areas on the turbine appeared. In the process the origin of the lightning leader, the angle of incidence and the prospective peak current of the leader were varied.

The outcome of the simulations was some plots of the downward leader tips at the moment where the inception of the successful connecting leader from the turbine occurs. Such a plot is seen in Fig. (3).

On this 3D plot, simulations concerning vertically incoming leaders with a prospective peak current of $60 \mathrm{kA}$ are considered. The different colors of the circles correspond to different attachment points on the structure, in this case the only attachment points were the two blade tips. Similar simulations were conducted for prospective peak currents of $40 \mathrm{kA}, 20 \mathrm{kA}$ and $10 \mathrm{kA}$, and with the rotor oriented in three different positions. Secondly simulations regarding incoming leaders inclined 45 degrees with vertical and exhibiting prospective peak currents of $30 \mathrm{kA}$ and $20 \mathrm{kA}$ were conducted.
To stress the situation even more, and find out whether attachments to side receptors or the nacelle is possible, a simulation was conducted where a leader approached vertically from directly above the nacelle. By varying the prospective peak current of this leader it was possible to define different attachment points for the same leader origin as seen in Fig. (4). In this figure, it is seen that for peak currents down to $8.5 \mathrm{kA}$, only the blade tips are exposed. When the peak current is lowered to $8.25 \mathrm{kA}$ or $8 \mathrm{kA}$, the fifth receptor pair is most exposed (20 m inboard the tip), whereas for currents below $8 \mathrm{kA}$, attachment to the rear of the nacelle occurs.

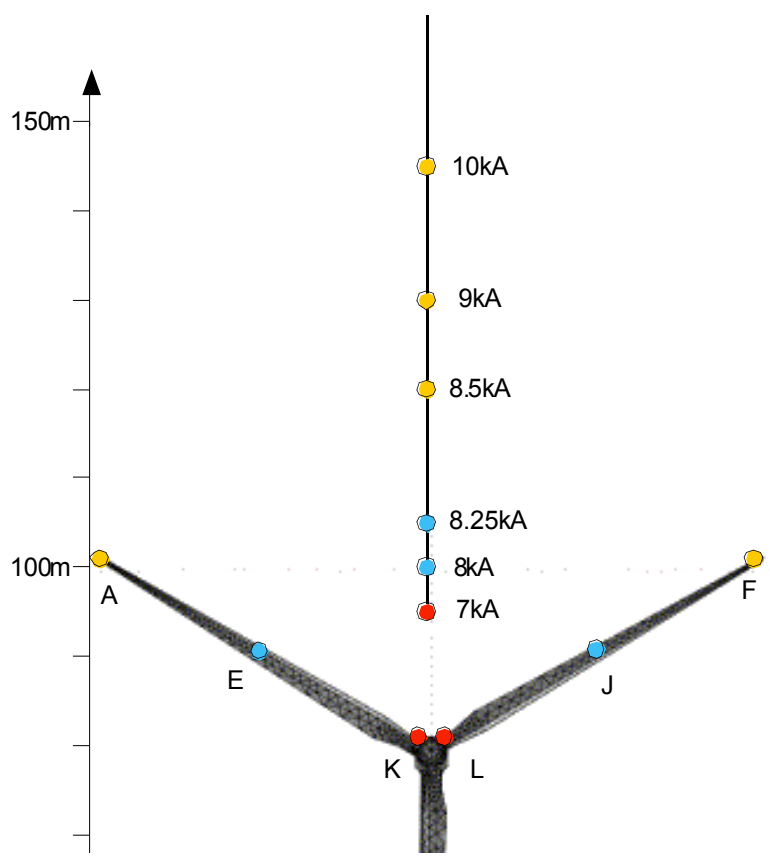

Fig. (4). Different attachment points are possible by varying the prospective peak return stroke current [11]. 
The overall results from the simulations were that only the blade tips are exposed to direct lightning attachment with peak currents exceeding roughly $10 \mathrm{kA}$. For lower prospective peak currents attachments inboard the tip is possible, but in such cases the structural damage will be limited. This research definitely points in the direction of a new zoning concept on blades.

Along the design of the newest offshore wind turbine platform, the Vestas V164-7MW, Fig. (5), numerical modeling of the lightning attachment distribution was also conducted. The blades on this model is $80 \mathrm{~m}$ long, so it was expected that the attachment point distribution would be slightly different than for the V90 turbine modeled previously.

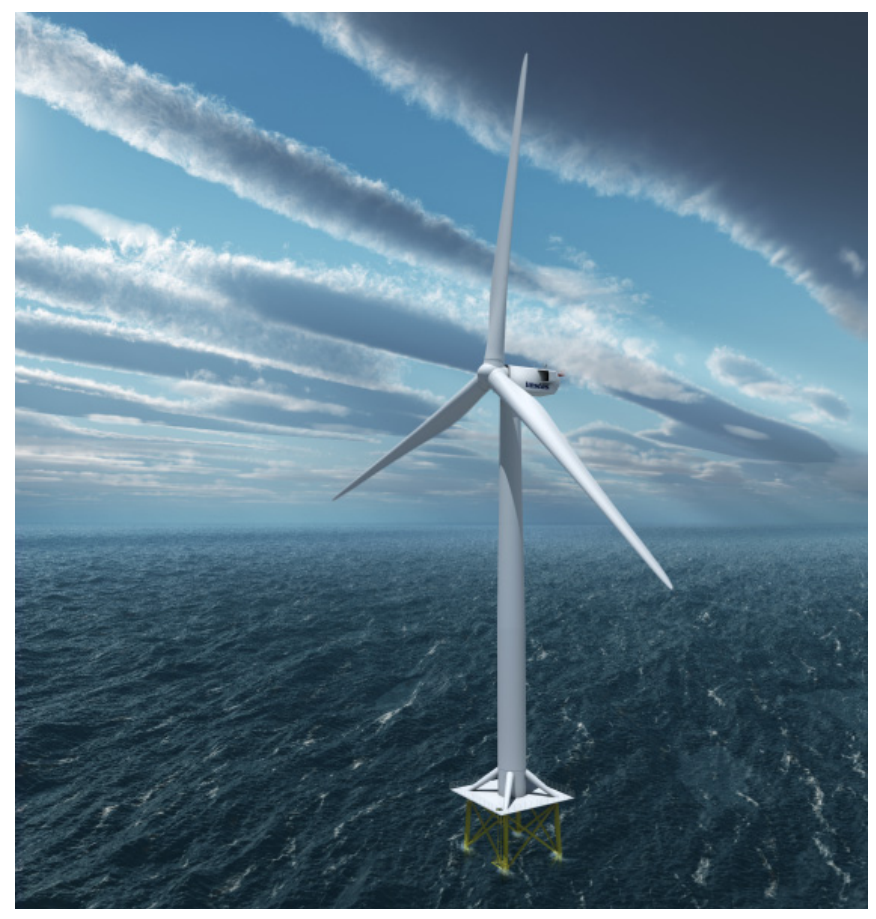

Fig. (5). The offshore wind turbine, Vestas V164-7MW [12].

The results were obtained with the rotor in the same three orientations as previously, having one blade oriented 30,60 and 90 degree with horizontal (Fig. 6).
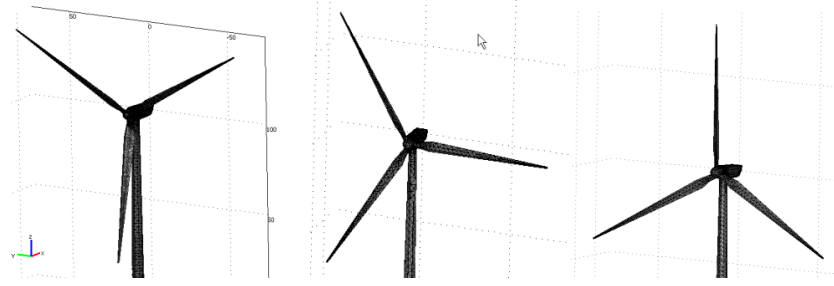

Fig. (6). Rotor orientations for the numerical simulations on lightning attachment points for the V164-7MW turbine.

The output of the simulations is the attachment point distribution along the length of the blades for prospective peak return stro ke currents between 10kA and 50kA. This is visualized on the graph on Fig. (7), indicating the probability of attachment $v s$ the distance from the blade tip for four specific prospective peak current amplitudes.

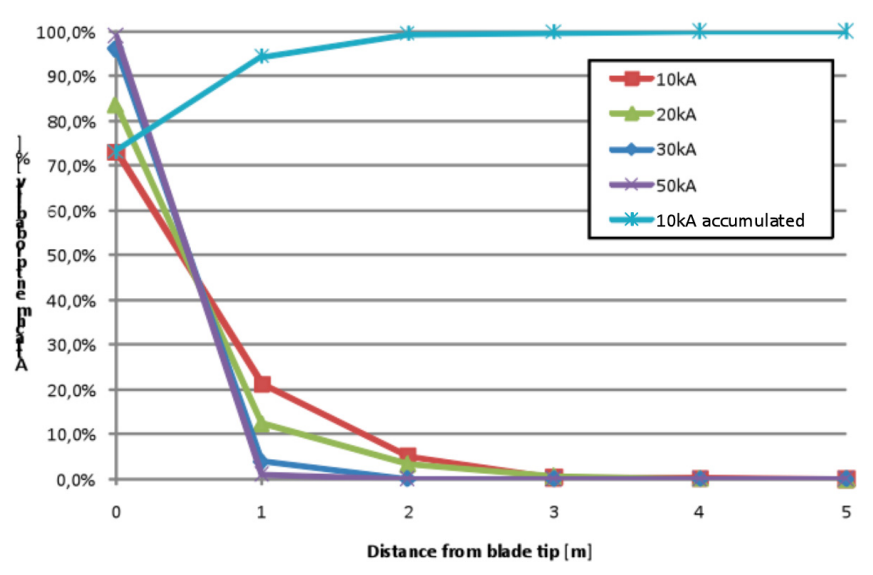

Fig. (7). Results on numerical simulations of the attachment point distribution on the V164-7MW turbine.

These curves show that considering even low amplitude strikes of $10 \mathrm{kA}$, the blades are not exposed to direct strikes further inboard than $4 \mathrm{~m}$ from the blade tips. Based on these simulations, the following statements then apply for strike attachment to $80 \mathrm{~m}$ blades with peak currents in excess of 10 $\mathrm{kA}$.

- $\quad$ The blades tip will intercept more than $70 \%$ of all naturally occurring lightning strikes of negative polarity.

- More than $90 \%$ of all naturally occurring negative lightning strikes will attach to the outermost $1 \mathrm{~m}$ of the blade.

- $\quad$ More than $99 \%$ of all naturally occurring negative lightning strikes will attach to the outermost $2 \mathrm{~m}$ of the blade.

- $\quad$ The attachment distribution moves towards the blade tip for increasing peak current amplitude.

Considering lower peak currents than $10 \mathrm{kA}$, attachment might occur inboard the radius described above. Secondly, the process preceding a correct attachment to the blade tip, might involve the inception of upward leaders several places. Some of these upward leaders might exhibit current amplitudes of a couple of $\mathrm{kA}$, sufficient to create a minor puncture in the blade skin inboard the lightning attachment point. These punctures are regarded as natural wearing phenomena. The upward leaders will eventually be quenched once the electric field collapses due to the attachment to the blade tip.

In general it is therefore believed that distinct lightning attachment with peak currents down to $10 \mathrm{kA}$ does not occur outside the regions described by these simulations. Upward leaders might however be incepted from the blade surface inboard this section, resulting in minor punctures but no direct lightning attachment.

If the probability density function from IEC 62305-1 describing the probability of strikes with certain peak currents is incorporated, the overall attachment point distribution along the length of the blade can be defined. The results are seen on Fig. (8). 


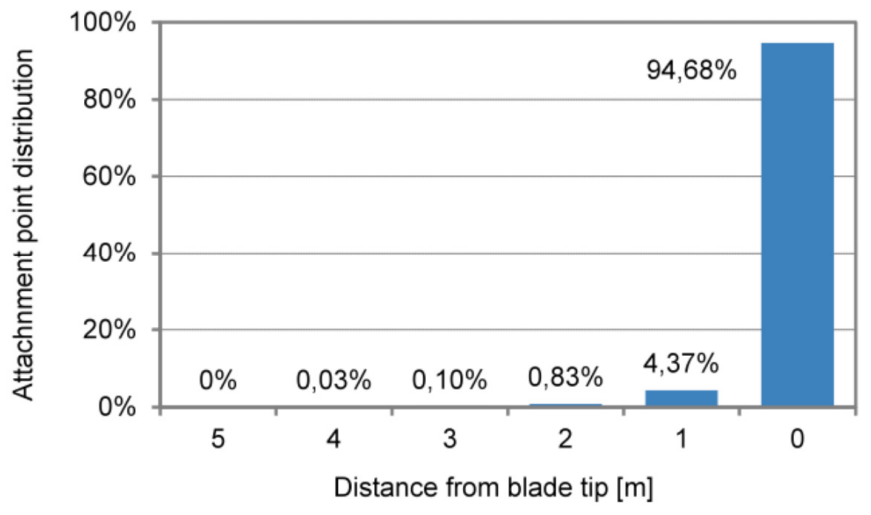

Fig. (8). Attachment point distribution accounting for the probability density functions of the lightning current parameters.

In order to develop an analytical tool to estimate the attachment point distribution the data in Fig. (8). is sought fitted with an exponential function. The match between the numerical results and the exponential function is seen on Fig. (9).

The numerical simulations therefore suggests an attachment point distribution according to the following equation, where $\mathrm{P}_{\text {blade }}$ is the probability of attachment [\%], and $\mathrm{d}$ is the distance from the blade tip [m].

$$
P_{\text {blade }}=0.5 \cdot \exp (-2.0 \cdot d)
$$

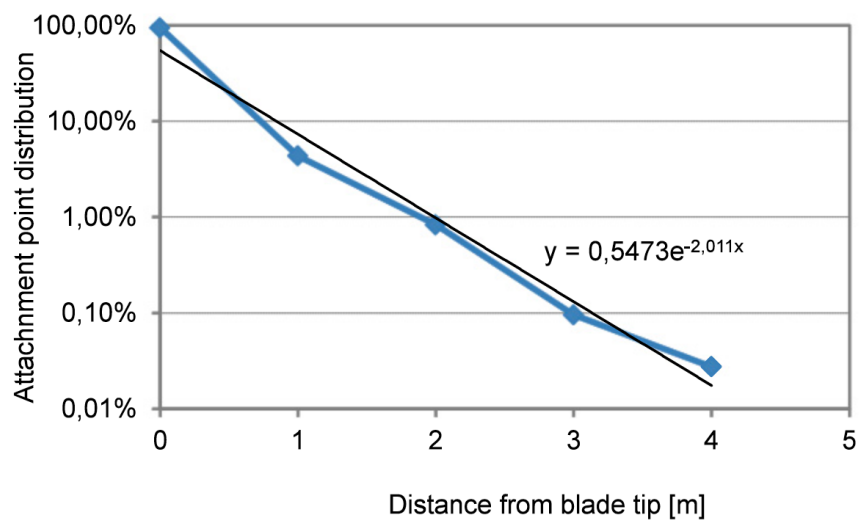

Fig. (9). Attachment point distribution fitted with an exponential function.

\section{FIELD SURVEY}

\subsection{Horns Reef Data}

The blades on the 'Horns Reef' wind farm, consisting of eighty turbines with $39 \mathrm{~m}$ blades, have all been investigated with respect to lightning attachments.

Out of the 236 blades exposed to lightning in 2 years a total of 118 lightning strikes were identified. 86 of these strikes attached either the tip receptors, 18 attached to the tip region but not to the tip receptors and 14 of them attached to the first pair of side receptors in radius $35 \mathrm{~m}$. In graphical form the attachment point distribution on the blades is seen on Fig. (10).

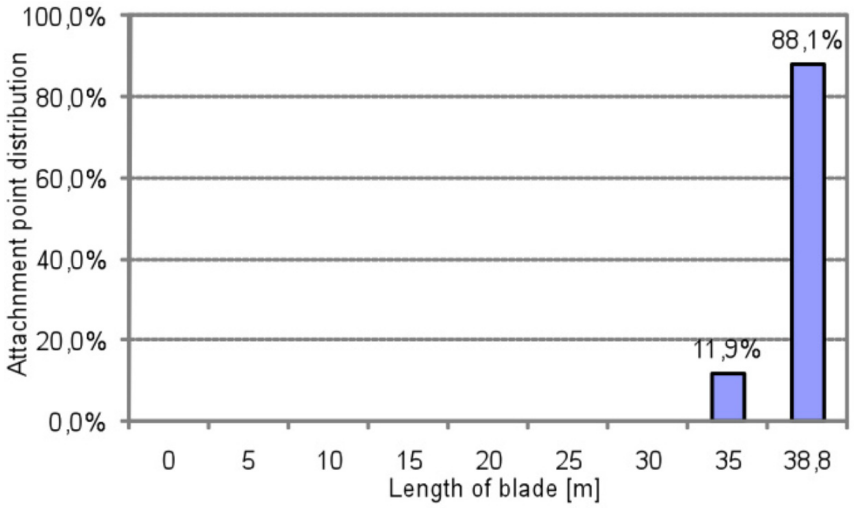

Fig. (10). Attachment point distribution on 236 blades $(39 \mathrm{~m})$ after two years of lightning exposure at the 'Horns Rev' wind farm.

Unfortunately it is not possible to correlate the attachment points with the actual lightning parameters, since only the resulting arcing on receptors and single damages are seen on the blades. However, it is pretty clear that the blade tip is by far the most exposed part of the blade, and that the absence of the third, fourth and fifth receptor pairs wouldn't change the picture. If the second receptor pair was removed it is also questioned whether the attachments to this region would have moved to the tip receptor instead.

A similar attempt of a correlation with an exponential function is done for the field data, by extrapolating the tendency $5 \mathrm{~m}$ to a distance of $10 \mathrm{~m}$ from the tip. The graph is shown on Fig. (11).

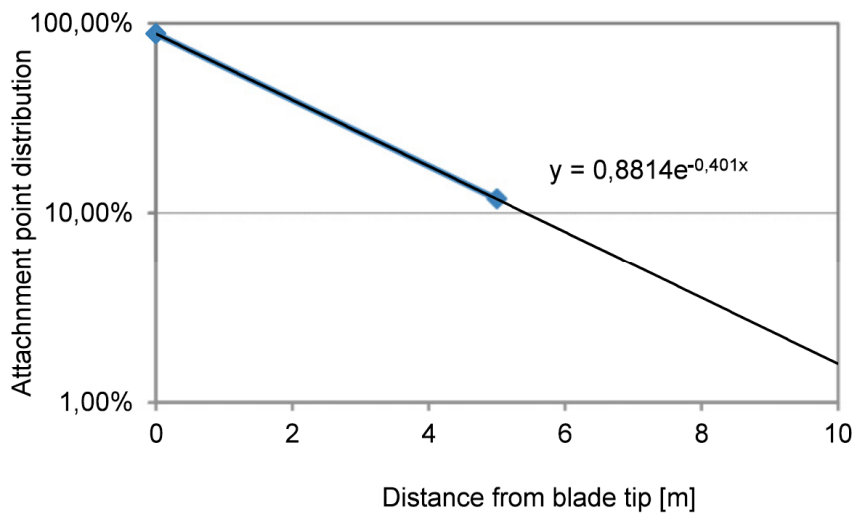

Fig. (11). Attachment point distribution from the field survey from Horns Reef, fitted with an exponential function.

The field survey from Horns Reef suggests an attachment point distribution according to the following equation, where $\mathrm{P}_{\text {blade }}$ is the probability of attachment [\%], and $\mathrm{d}$ is the distance from the blade tip [m].

$$
P_{\text {blade }}=0.9 \cdot \exp (-0.4 \cdot d)
$$

\subsection{Site Inspections 2010}

During spring of 2010, a large site inspection program has been conducted. 40 turbines with a total of 120 blades ( $45 \mathrm{~m}$ length) have been inspected visually, and data considering the attachment point distribution on the blade 
surfaces has been recorded. The locations of the turbines are chosen to cover a wide range of possible sites worldwide, sites that are prone to a fairly intense lightning environment.

The data set includes a total of 2818 identified lightning attachment points, the attachment point distribution of which is seen in Fig. (12). Within these data, the picture is quite clear. $70 \%$ of the lightning attachments occur to the outermost $1.5 \mathrm{~m}$ of the blade, $20 \%$ occur within $1.5-6 \mathrm{~m}$ from the blade tip, and the remaining $10 \%$ occured further inboard.

The main conclusion from the recent site inspection program is therefore that the tip of the blades (within $1.5 \mathrm{~m}$ ) receives $70 \%$ of the lightning strikes, $90 \%$ of the lightning strikes attaches within the outermost $6 \mathrm{~m}$ of the blade, and that the remaining $10 \%$ attaches further inboard $(6 \mathrm{~m}$ from the tip). No correlations have been done so far considering the size of the erosion on receptors and hence the current peak amplitude / specific energy / charge levels, but will be published in the future.

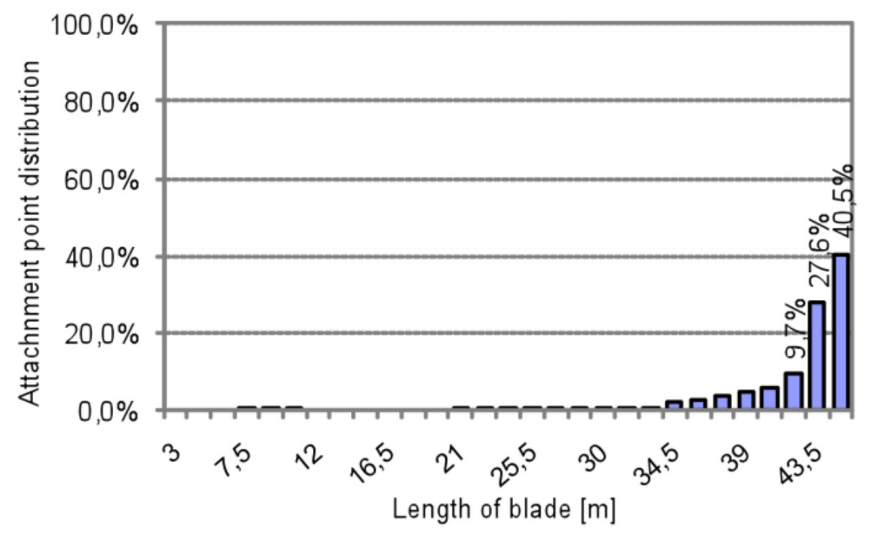

Fig. (12). Attachment point distribution of 2818 identified lightning attachment points on $45 \mathrm{~m}$ blades.

The correlation of the attachment distribution from Fig. (12) is performed in Fig. (13) with an exponential function.

In Fig. (13) a third correlation is found with the following equation.

$$
P_{\text {blade }}=0.2 \cdot \exp (-0.3 \cdot d)
$$

\subsection{Site Inspection 2011}

Some of the wind turbines were re-inspected in 2011, to investigate the estimated lifetime of a specific type of receptor system. 18 blades that have been in operation for approximately one year were investigated and a total of 318 lightning strikes were identified. The receptor system considered a copper cap on the blade tip connected to an inner down conductor. Along the sides of the blades, additional air terminations were mounted $3 \mathrm{~m}$ and $6 \mathrm{~m}$ from the blade tip. On the surface of the blade, a conductive strip (100 $\mathrm{mm}$ wide and $0.5 \mathrm{~mm}$ thick) was connecting the two side receptors and extended nearly to the blade tip. The purpose of the conductive strip is to increase the interception effectiveness, which proved to be the case.

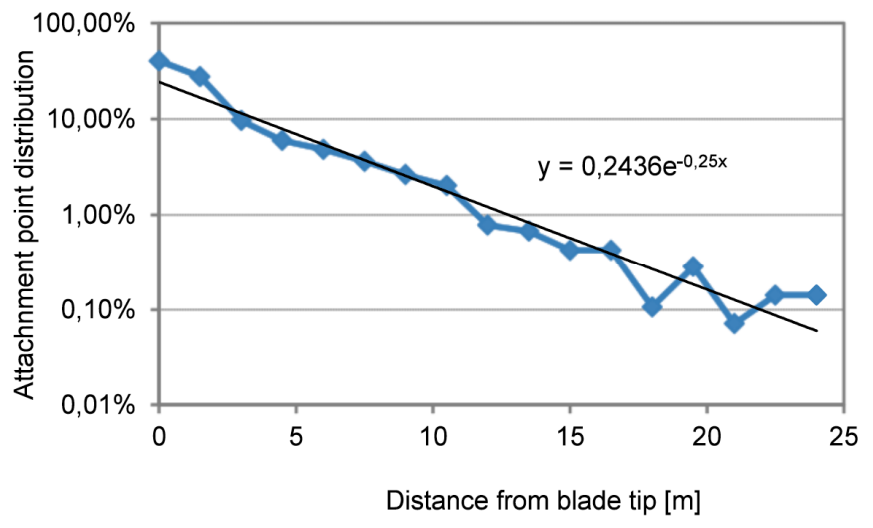

Fig. (13). Attachment point distribution from the field survey 2010, fitted with an exponential function.

Out of the 318 identified lightning attachments 208 $(65 \%)$ attached to the tip receptor, whereas the remaining $110(35 \%)$ attached to the conductive strip along the length of the blade. No attachments had occurred outside the intended air termination system. A drawing of the protection principle is to be seen in Fig. (14).

A second very interesting observation was that the distribution of the attachment points on the conductive strip showed that the vast majority of the attachments occurred to the tip of the copper strip, whereas only two attachments were observed between the two special receptors in Fig. (14). In general terms, the attachment distribution found in the field survey of 2011 showed that $99.4 \%$ attached to the outermost meter of the blade whereas only $0.6 \%$ attached between $3 \mathrm{~m}$ and $6 \mathrm{~m}$ from the tip. The attachment point distribution and the correlation with an exponential function are seen in Fig. (15).

In Fig. (15) a fourth correlation is found with the following equation.

$$
P_{\text {blade }}=0.8 \cdot \exp (-1.1 \cdot d)
$$

\subsection{Strike Data Outside Vestas}

A paper by V. Peesapati [13], published in the IET Renewable Energy Journal, analyzed lightning data from the

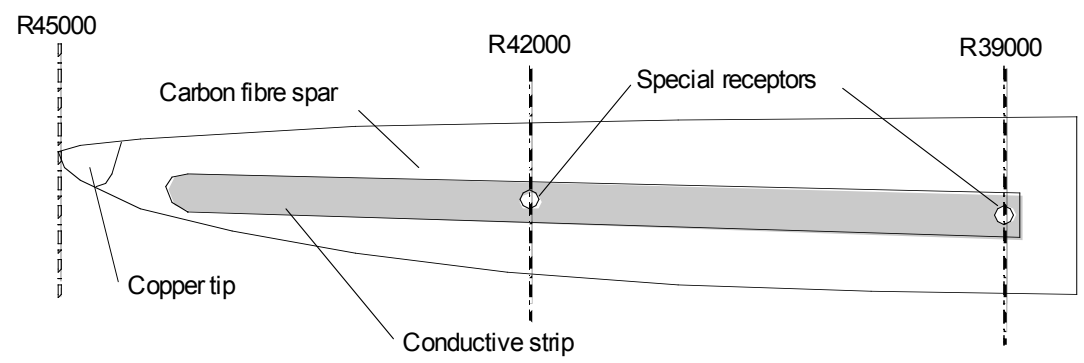

Fig. (14). Protection principle of the blades investigated during the field survey 2011. 
Nysted Wind farm and a larger data set from 450 turbines worldwide.

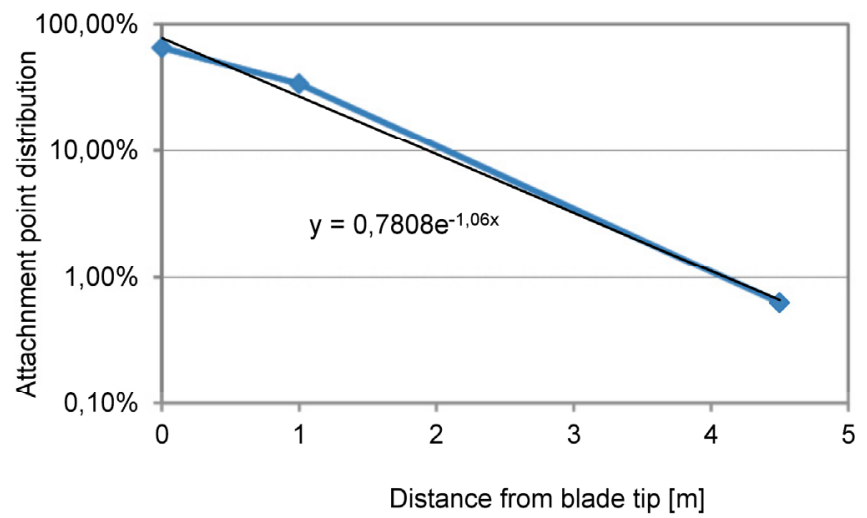

Fig. (15). Attachment point distribution from the field survey 2011, fitted with an exponential function.

The data from Nysted Wind Farm consisted of correlated readings between the lightning registration system by Jomitek, and the PCS card readings from different parts of the turbine. Several statistical approaches are used to clarify the validity of the data and remove obvious misinterpretations. Based on the readings of peak currents in each blade root, and several other places in the structure (air termination systems for the wind vane, the aviation light etc.), it seems that the blades are exposed to the highest current amplitudes.

Unfortunately the position of the measurement system does not allow for a discrepancy between attachment points $v s$ amplitude within the blades. However, the tendency that blades experience higher current readings than the installations at the rear of the nacelle, still shows that the pointiest and most elevated part of the structure experience the largest peak currents.

The second data set that has been analyzed in [13] comes from wind farms all over the world. The database contains records of over 450 wind turbines, and their lightning registrations over a 6 year period $(2000-2006)$. Data from more than 1800 PCB card readings were analyzed, and despite the difficulties in analyzing such data reliably, the conclusions are fairly the same as from Nysted wind farm.

As an example it is seen that app. $25 \%$ of peak currents to the blades worldwide exceed 20kA, whereas the value for wind vanes globally is $15 \%$. Again it seems as if the higher amplitude strikes are more likely to attach to the pointiest part of the structure.

Several other conclusions are derived based on the reviewed data. For example that the peak current of attachment to blades are lower when the turbines are placed offshore compared to onshore installations, and that many of these strikes could be upward initiated. A second interesting finding is that only in one case out of 1800 card readings had the peak current exceeded $120 \mathrm{kA}$.

\subsection{Final Correlation of Data}

The purpose of this research is to initiate the discussion on how the attachment process on wind turbine blades can be defined. Based on the numerical modeling, and the three different field surveys (Horns Reef, 2010, 2011), it has been possible to establish exponential functions describing the attachment point distribution and fitted with the actual data. In Fig. (16). four different equations are plotted along with a function fitted with the average values as predicted by the four individual equations.

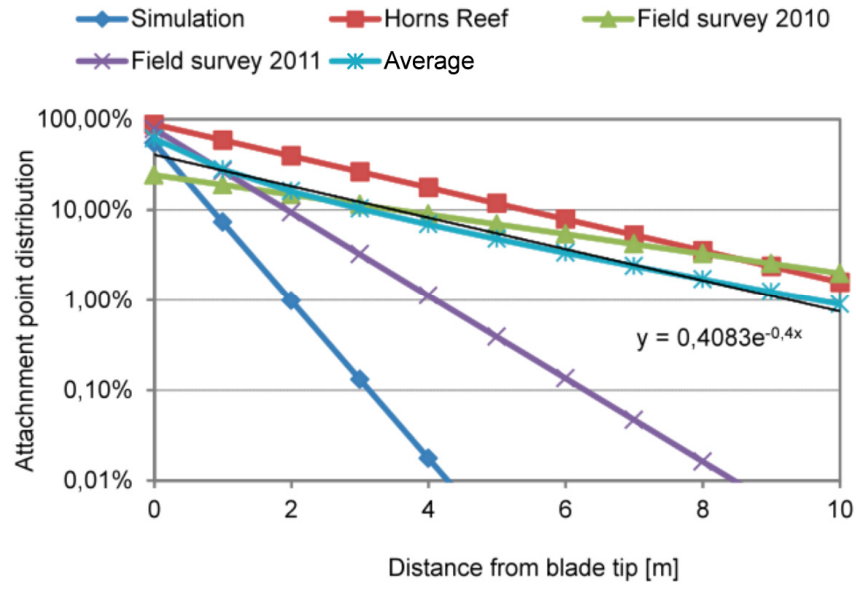

Fig. (16). The attachment point distributions from the four different equations derived (eq. 5, 6, 7, 8) along with a function fitted with average values of the four distributions.

As seen in Fig. (16). the average values fit better to the Horns reef and the Field survey of 2010, than to the 2011 Field survey and the simulations. The reason for this is that the two first cases consider blades with discrete air terminations at the tip and every $5 \mathrm{~m}$ from the tip towards the root, whereas the site survey 2011 and the simulations basically allow attachments along the entire length of the blade tip. The consequence of this is that the attachments move further outboard when the air terminations are present at the entire length.

All the gathered information on attachment point distribution on modern wind turbine blades can therefore be expressed as an exponential function as seen in equation 9, where $\mathrm{P}_{\text {blade }}$ is the probability of attachment [\%], and $\mathrm{d}$ is the distance from the blade tip [m].

$$
P_{\text {blade }}=0.4 \cdot \exp (-0.4 \cdot d)
$$

Having this equation defined, and assuming that the strikes with the largest amplitudes will attach to the outermost tip, it is possible to distribute the expected strike amplitudes along the length of the blade according to the probability density function in IEC 62305-1. In the second column of Table $\mathbf{2}$, the accumulated probabilities of attachment as defined by equation 9 . are listed along with the distance from the blade tip. In the third column, the corresponding lightning current amplitude found in the probability density functions of IEC 62305-1 is shown.

Basically the idea is that if $41 \%$ of all lightning strikes attach to the tip, and since these lightning strikes are expected to exhibit the highest peak currents, all strikes down to amplitude of $57 \mathrm{kA}$ will strike the tip. Likewise since $68 \%$ of all strikes attach within one meter from the tip, it corresponds to all strikes down to amplitudes of 36kA. Relating these suggestions to a practical design guideline, it means that the protection of the blade surface for specific distances from the tip should exceed the levels in the third column of Table 2. 
Table 2. The Accumulated Probability of Attachment and the Minimum Current Amplitude vs Distance from the Blade Tip

\begin{tabular}{|c|c|c|}
\hline $\begin{array}{c}\text { Distance from } \\
\text { Tip [m] }\end{array}$ & $\begin{array}{c}\text { Accumulated } \\
\text { Probability of } \\
\text { Attachment [\%] }\end{array}$ & $\begin{array}{c}\text { Minimum Amplitude Acc. } \\
\text { to Probability Density } \\
\text { Function }\end{array}$ \\
\hline \hline 0 & 41 & 57 \\
\hline 1 & 68 & 36 \\
\hline 2 & 87 & 26 \\
\hline 3 & 99 & 6 \\
\hline
\end{tabular}

\section{NEW ZONING CONCEPT}

All the statements above based on lightning physics, numerical modeling and site inspections, suggests that the attachment point distribution on blades is different from what is traditionally believed. The different approaches consider blade lengths of $39 \mathrm{~m}, 40 \mathrm{~m}, 45 \mathrm{~m}$, and $80 \mathrm{~m}$, and the zoning concept applies to blades within this range. Academically speaking, there is a limit of how long a blade could be before lightning attachment to the middle section is unaffected by the presence of the tip. This discussion is not relevant for $80 \mathrm{~m}$ blades and lightning strikes down to $10 \mathrm{kA}$, but might be considered when the turbine models are investigated with even lower amplitude strikes. For convenience, the example given in this paper considers a typical blade length of $40 \mathrm{~m}$.

The attachment point distribution is believed to depend on the installation of air terminations and the down conductor system, meaning that an uncovered internal down conductor will invite more attachments than a well insulated conductor. Since the zoning concept is derived based on inspections of blades with standard down conductor installations, and models considers an all metal blade surface, it is believed that improved installation techniques will only push the attachment points further outboard. The presented zoning concept therefore considers the worst case scenarios when it comes to blade design.

\subsection{Sectioning the Blade}

It has been decided to divide the blade into four sections as a subdivision of the traditional Zone $0 \mathrm{~A}$ and $0 \mathrm{~B}$, based on the maximum peak current amplitudes to be expected. The zoning concept only considers the longitudinal aspects of the blade; hence no concerns are given to special geometries of trailing edges, tips, etc. The zoning concept is seen in Fig. (17).

Since the blade tip appears to be the only part of the blade exposed to the full lightning current, it is decided to assign the outermost $1 \mathrm{~m}$ of the blade to a Lightning Protection Zone $0 \mathrm{~A}_{1}$. This means that the blade tip must be designed to intercept lightning strikes of all current amplitudes, and must withstand the impact from the impulse current with the highest amplitude according to the IEC standards, i.e. $200 \mathrm{kA}$. The impulse current test waveform for the Zone $0 A_{1}$ is then the $10 / 350 \mu$ s pulse having peak current amplitude of $200 \mathrm{kA}$, a specific energy of $10 \mathrm{MJ} / \Omega$, and a conducted charge of $100 \mathrm{C}$. During testing, the long stroke will apply the same amount of charge as specified for LPL1 in [1-2], i.e. a total of $300 \mathrm{C}$ for the entire flash.

The second zone for the direct attachments is Zone $\mathrm{OA}_{2}$, which covers the blade the next 4 meters, from $1 \mathrm{~m}$ from the tip to $5 \mathrm{~m}$ from the tip. In this area the peak amplitude current of the lightning strikes expected to attach here is far less than for Zone $0 A_{1}$. The protection system installed in this area must intercept all strikes defined by the strike attachment test suggested in [1], and then secondly be able to conduct a stroke current of $100 \mathrm{kA}$. The $100 \mathrm{kA}$ stroke current for the Zone $\mathrm{OA}_{2}$ is in the IEC [1] defined as a $10 / 350 \mu$ s pulse having a peak current amplitude of $100 \mathrm{kA}$, a specific energy of $2.5 \mathrm{MJ} / \Omega$, and a conducted charge of 50 C. According to [1-2] the total conducted charge for both the first short stroke and the long stroke is $150 \mathrm{C}$.

The third section of the blade exposed to direct attachment is Zone $\mathrm{OA}_{3}$, from $5 \mathrm{~m}$ inboard the blade tip to $20 \mathrm{~m}$ inboard the blade tip. In this area the installed air termination system must again intercept all lightning strikes as verified by the strike attachment test, but this time the expected peak amplitude of the stroke currents is a maximum of $50 \mathrm{kA}$. The current test waveform for this Zone $0 \mathrm{~A}_{3}$ is then a $10 / 350 \mu$ s pulse with peak amplitude of $50 \mathrm{kA}$, a specific energy of $0.63 \mathrm{MJ} / \Omega$, and a conducted charge of $25 \mathrm{C}$. Extrapolating the values in [2], the charge injected during the long stroke must be $50 \mathrm{C}$, such that the total charge injected during both impacts amounts to $75 \mathrm{C}$.

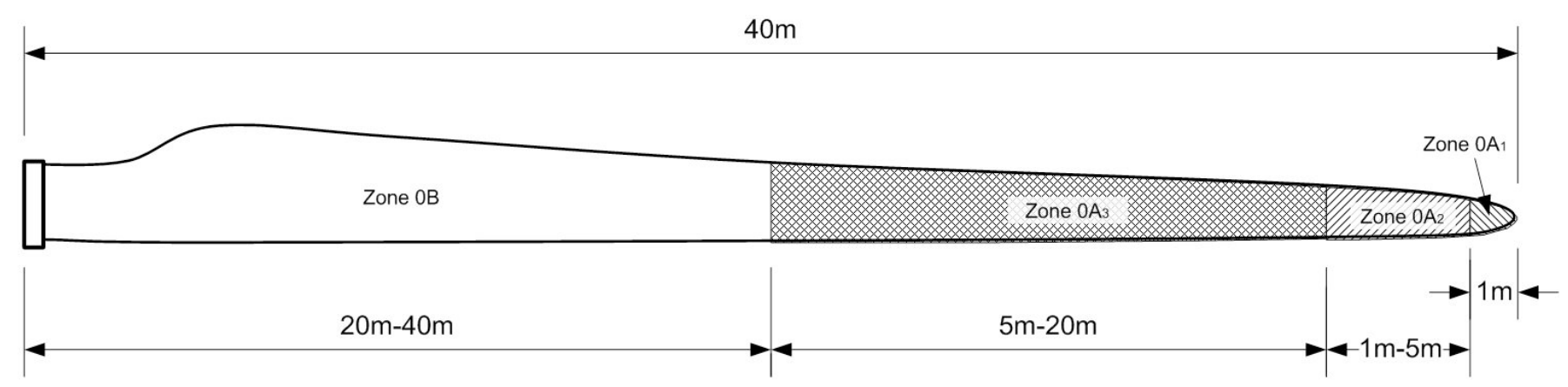

Zone $\mathrm{OA}_{1}$ : Tip end to $1 \mathrm{~m}$ inboard, $<200 \mathrm{kA}$

Zone $\mathrm{OA}_{2}$ : $1 \mathrm{~m}$ inboard to $5 \mathrm{~m}$ inboard, $<100 \mathrm{kA}$

Zone $\mathrm{OA}_{3}$ : $5 \mathrm{~m}$ inboard to $20 \mathrm{~m}$ inboard, $<50 \mathrm{kA}$

Zone OB: $20 \mathrm{~m}$ inboard to root end, no direct attachments

Fig. (17). New zoning concept based on the expected peak current amplitudes. The distances are measured from the blade tip. 
The last zone of the blade is Zone $0 \mathrm{~B}$ from $20 \mathrm{~m}$ from the tip to the root end. Here the blade will experience the full magnetic field and the full lightning current, as the current from a successful lightning interception in Zone $0 \mathrm{~A}_{1}$, Zone $0 \mathrm{~A}_{2}$ or Zone $0 \mathrm{~A}_{3}$ passes along the down conductor. This part of the blade will during the verification process only be exposed to conducted current tests.

The zoning concept and the current parameters suggested initially at ICLP'2010 [14] are selected with a large margin to the minimum amplitudes acc. to Table 2 . Since the concept is rather conservative and has a huge impact on future blade design, it is of course a topic for further discussion in the lightning and wind turbine community.

\subsection{Strike Attachment Tests}

The practical application of the zoning concept does still rely on proper designing and verification by $\mathrm{HV}$ strike attachment tests. This means that although the entire outermost $1 \mathrm{~m}$ blade tip is located within Zone $0 \mathrm{~A}_{1}$, the 200 $\mathrm{kA}$ stroke current must not necessarily be injected in all points at the surface during testing. If a blade strike attachment test has been conducted, and proves that the intended air termination of the tip will incept all the discharges, the $200 \mathrm{kA}$ stroke currents must only be injected into the air termination system.

This also applies to the Zone $0 \mathrm{~A}_{2}$ and Zone $0 \mathrm{~A}_{3}$, where strike attachment tests might show that the installed air termination system will protect the remaining part of the blade. If so, only the $100 \mathrm{kA}$ and the $50 \mathrm{kA}$ stroke currents must be injected into the air termination systems.

\section{DISCUSSION}

Considering lightning protection of wind turbine blades and associated testing, especially two parameters of the lightning current have proven to be important. This regards the peak amplitude current, and related to testing, therefore also the specific energy, and secondly the conducted charge. The specific energy is responsible for the thermal heating once the lightning current has entered the down conductor, whereas the charge is responsible for erosion on the surface of the air termination.

The presented zoning concept is based on the evidence that mainly the blade tips experience average to high amplitude direct lightning strikes. Therefore a system fulfilling the zoning concept could consist of smaller air terminations in Zone $0 \mathrm{~A}_{2}$ and Zone $0 \mathrm{~A}_{3}$, well suited for the reduced peak amplitude and specific energy. However, since no unique correlation between the peak current and the total charge in the flash exists, these smaller air terminations might suffer from unexpected high charge content in low amplitude lightning strikes.

The issue is probably most relevant with respect to testing, since the charge levels in the standardized tests [1-2] are much higher than the median values for the lightning current parameters. If there correlation exists between the total charge in the flash and the peak current, it might have an influence on the current zoning concept.

Recently an arc attachment study has been initiated, where the arc root erosion on different metal surfaces are evaluated and compared with the images of actual lightning attachments from the three different site surveys. This will enable a better evaluation of the current parameters of the strikes identified. By knowing both the attachment point distribution and a good estimation of the associated peak current value, the equations identified from the site surveys in the present research can be improved considerably.

The results will be published in near future, and contribute to the understanding that high peak current amplitude lightning strikes do not attach to the blade surface several meters inboard the tip.

\section{CONCLUSION}

Four different means of investigating the lightning attachment distribution on wind turbine blades have been presented. Numerical modeling as well of field surveys conducted on three different sites have been conducted, all of them indicating that the tip is more exposed than the remaining part of the blade. Based on the data, an equation linking the probability of attachment with the distance from the blade tip is suggested governing blades with lengths of 40-80m

$P_{\text {blade }}=0.4 \cdot \exp (-0.4 \cdot d)$

where $\mathrm{P}_{\text {blade }}$ is the probability of attachment [\%], and $\mathrm{d}$ is the distance from the blade tip [m]. For curiosity, the distribution is correlated with the probability density function from the IEC 62305-1, indicating once more that the blade tip and the outer most meters of the blade is prone to the highest amplitude strikes.

Secondly a new zoning concept for placing and designing the lightning protection system on wind turbine blades is presented. Based on the previous findings, the concept divides the blade into four different lightning protection zones. The first zone 'Zone $0 \mathrm{~A}_{1}$ ' consider the outermost $1 \mathrm{~m}$ of the blade tip and will be exposed to full amplitude lightning strikes of $200 \mathrm{kA}$. The second zone 'Zone $0 \mathrm{~A}_{2}$ ' considers the blade tip from $1 \mathrm{~m}$ inboard the tip to $5 \mathrm{~m}$ inboard the tip, and is exposed to $100 \mathrm{kA}$ peak current.

The third zone 'Zone $0 \mathrm{~A}_{3}$ ' considers the blade from $5 \mathrm{~m}$ inboard the tip to $20 \mathrm{~m}$ inboard the tip, and is only exposed to $50 \mathrm{kA}$ peak current. The final zone is the remaining part of the blade, 'Zone 0B', not exposed directly to lightning attachment.

The new zoning concept will probably change the basis for the air termination system in number or size, why the cost of the total lightning protection system is expected to decrease. Once the attachment point distribution from the different field surveys has been correlated with arc entry tests currently being performed, the zoning concept and the current parameters defining it will be updated. When the concept has gained acceptance in the lightning community, it is strongly suggested to get it implemented in the international standards on the subject.

\section{ACKNOWLEDGEMENT}

Declared none.

\section{CONFLICT OF INTEREST}

Declared none. 


\section{REFERENCES}

[1] IEC 61400-24. Wind turbines: part 24: lightning protection. 24 ed. 1.0 (CDV) 2009.

[2] IEC 62305-1. Protection against lightning. Part 1: general principles. $1^{\text {st }}$ ed 1.0 IEC 2006.

[3] IEC TR 61400-24: Wind turbine generator systems. Part 24: lightning protection. 24 ed 1.0 IEC 2002.

[4] Uman MA. The lightning discharge. Dover Publications: INC, Mineola, New York 1961.

[5] Rakov VA, Uman MA. Lightning, physics and effects. Cambrige University Press: New York 2003.

[6] Becerra M, Cooray V. A simplified model to represent the inception of upward leaders from grounded structures under the influence of lightning stepped leaders. Proceedings of the international conference on lightning and static electricity. Seattle Washington, USA, September 2005.

[7] Becerra M, Cooray V, Abidin HZ. Location of the vulnerable points to be struck by lightning in complex structures. proceedings of the international conference on lightning and static electricity; 2005 Sep; Seattle Washington, USA 2005.

[8] Becerra M, Cooray V. A simplified physical model to determine the lightning upward connecting leader inception. IEEE Trans Power Deliv 2006; 21(2): 897-908.
[9] Bertelsen K, Erichsen HV, Jensen SMVR, Madsen SF. Application of numerical models to determine lightning attachment points on wind turbines; Proceedings of the international conference on lightning and static electricity; 2007 Aug 28-31; Paris, France.

[10] Madsen SF. Erichsen HV. Improvements of numerical models to determine lightning attachment points on wind turbines; Proceedings of the 29th international conference on lightning protection; 2008 June 23-26; Uppsala, Sweden.

[11] Madsen SF, Erichsen HV. Numerical model to determine lightning attachment point distributions on wind turbines according to the revised IEC 61400-24; Proceedings of the international conference on lightning and static electricity; 2009 Sep 15-17; Pittsfield MA, USA.

[12] Vestas Wind Systems. Available at http://www.vestas.com

[13] Peesapati V, Cotton I, Sorensen TS, Krog T, Kokkinos N. Lightning protection of wind turbines: a comparison of measured data with required protection levels. IET Renewable Energy J 2011; 5(1): 48-57.

[14] Madsen SF, Bertelsen K, Krogh TH, Erichsen HV, Hansen AN, Lønbæk KB. Proposal of new zoning concept considering lightning protection of wind turbine blades. Proceedings of the international conference on lightning protection; 2010 Sep 12-16; Calgari, Italy, 